\title{
Ability of Saudi mothers to appropriately and accurately use dosing devices to administer oral liquid medications to their children
}

This article was published in the following Dove Press journal:

Drug, Healthcare and Patient Safety

22 December 2014

Number of times this article has been viewed

\section{Saja Almazrou \\ Hind Alsahly \\ Huda Alwattar \\ Lamya Alturki \\ Mona Alamri}

Department of Clinical

Pharmacy, College of Pharmacy, King Saud University, Riyadh,

Saudi Arabia
Correspondence: Saja Almazrou Department of Clinical Pharmacy, College of Pharmacy, King Saud University, PO Box 2627, Riyadh 12372-7524, Saudi Arabia Tel +966506253883

Email salmazrou@ksu.edu.sa
Background: Most liquid medications are packaged with administration devices, which may be used inappropriately or inaccurately, and sometimes are not used at all. Because of the importance of their proper use for children's health, this study was designed to assess Saudi mothers' experiences with measuring cups, syringes, and droppers for oral liquid medications; to compare accuracy of dosing across these devices; and to determine the effects of mothers' education statuses and pharmacist counseling on dosing accuracy.

Methods: This was a cross-sectional study in which mothers were observed as they used a set of commonly available dosing devices which are a dosing cup, syringe, and dropper. Interviews were conducted in the outpatient pharmacy waiting area in several tertiary hospitals and primary clinics in Riyadh, Saudi Arabia between March and April 2013. Saudi women who were mothers of children aged 12 years old or younger and who gave their consent were eligible. Caregivers other than mothers and subjects with vision problems or cognitive/physical disabilities were excluded. We gathered demographic information such as age, number of children, and education status. Subjects were asked if they had had counseling on how to use measuring devices and which device they preferred. Then, the mothers were required to demonstrate how to measure $5 \mathrm{~mL}$ of paracetamol (acetaminophen) syrup using a cup and a syringe and $1 \mathrm{~mL}$ of paracetamol syrup using a dropper. Dosing errors were evaluated visually as overdosing, underdosing, or no error (if the dose was accurate). The data were entered into Microsoft Excel and evaluated using Stata 11.1. Logistic regression was employed to determine relationships.

Results: The results revealed that $58 \%$ of participants measured an accurate dose of paracetamol using the oral dosing syringe versus $50 \%$ of participants using the dropper and $51 \%$ using the dosing cup. In general, participants measured more than the intended dose with the dosing cup and less than the intended dose with the dropper. Furthermore, we found that dosing accuracy for each type of instrument was significantly influenced by the mothers' education status. Among the study participants, $77 \%$ had not had previous counseling on the use of liquid medication measuring devices. However, dosing errors were not affected by previous counseling.

Conclusion: Among mothers using measuring devices, the most accurate doses were found to be measured with the use of the oral syringe, whereas the most errors were made with the use of the dropper. Moreover, education status had a significant effect on dosing errors. The use of a pictographic diagram could improve the mothers' dosing abilities and, thus, reduce dosing errors.

Keywords: paracetamol, syringe, cup, dropper, accurate, education, counselling

\section{Introduction}

Medication errors are any errors that occurs in the medication use process. ${ }^{1}$ Examples of these errors include the wrong dosage prescribed and the wrong dosage administered for a prescribed medication. Many prescription and over-the-counter (OTC) 
medications are available in liquid formulations. More than $50 \%$ of 3 -year-old children have received at least one OTC product. ${ }^{2}$ Most liquid medications are packaged with devices for administration. The dosing devices may be used inappropriately or inaccurately or, at times, not be used at all. Recent reviews identified several factors associated with acetaminophen hepatotoxicity in children, including; age less than 10 years associated with inappropriate dosing, delays in onset of symptoms after a potentially toxic ingestion and ingestion of acetaminophen along with another hepatotoxic drug. ${ }^{3}$ Also, a significant portion of the population underdoses when giving acetaminophen, reflecting lack of knowledge or misuse. Based on parental reports, the majority of visits to the Emergency department for fever might have been prevented if parents had been successful in their effort to reduce their child's temperature to below what they considered to be fever. ${ }^{4}$ These reports are of special concern because OTC liquid drug products are frequently intended for young children, for whom dosing errors can be especially serious. ${ }^{5}$ Mothers play a key role in child therapy, as they are considered to be intermediaries between prescribers and the child. Due to lack of communication between children and mothers, socioeconomic status, educational challenges, and cultural attitudes, medication errors might arise. One study showed that $6 \%$ of parents believed that acetaminophen was safe to administer in unlimited amounts and that nearly one-third of parents administered more than the recommended dose of acetaminophen to their children. ${ }^{2}$

In summary, dosing errors might negatively affect the optimization of pediatric health, safety and well-being. Therefore, factors that may affect the dosing ability of caregivers should be determined to propose a practical solution to this issue.

To our knowledge, no previous studies have been conducted in Saudi Arabia and the Middle East countries to assess mothers' dosing abilities in measuring liquid medication. Therefore, this study was designed to assess Saudi mothers' experiences with measuring cups, syringes, and droppers for oral liquid medications; to compare the accuracy of dosing across these devices; and to determine the effects of mothers' education statuses and pharmacist counseling on dosing accuracy.

\section{Methodology}

This was a cross-sectional study in which mothers were observed as they used a set of commonly available dosing devices which are a dosing cup, syringe, and dropper.
Interviews were conducted in the outpatient pharmacy waiting area in several tertiary hospitals and primary care clinics in Riyadh, Saudi Arabia between March and April 2013. A letter was sent to the director of pharmacy in each setting to explain the objective of the study and request permission to conduct the study in the hospital/ clinic. In the study settings, an institutional review board is not required to conduct interviews and noninterventional studies. Therefore, pharmacy directors were consulted and they suggested obtaining verbal consent from each participant.

The interviews were performed by third- and fourthyear pharmacy students. A meeting was scheduled with the researchers to explain the study and to familiarize the students with the devices and the data collection tool.

A convenience sample of 575 Saudi mothers of children who were 12 years old or younger were eligible and gave their verbal consent. The rationale for choosing this age group was according to the Fevadol ${ }^{\circledR}$ (paracetamol [acetaminophen]) package insert statement regarding oral liquid paracetamol use in children 12 years and younger. ${ }^{6}$ Subjects with vision problems, cognitive/physical disabilities, and caregivers other than mothers were excluded.

The students approached participants while they were in the outpatient pharmacy waiting area. The students explained the aim of the study and informed each participant that their demographic information would be used for research purposes and that their participation is entirely voluntary. No incentives were offered to increase response rate.

Demographic information such as age, number of children, and education status were gathered. Subjects were also asked if they had received counseling on how to use measuring devices and which device they prefer. Then, the mothers were required to demonstrate how to measure $5 \mathrm{~mL}$ of paracetamol syrup using a cup and a syringe and $1 \mathrm{~mL}$ of paracetamol syrup using a dropper. Dosing errors were evaluated visually as overdosing, underdosing, or no error (if the dose was accurate).

The data were entered into Microsoft Excel, and the results of the survey were evaluated using Stata 11.1. Descriptive statistics (frequencies and percentages) were used to depict the sociodemographic characteristics of study participants. Multinomial logistic regression was used to determine the effects of participant demographics on dosing error for each device. For all analyses, two-tailed $P<0.05$ was considered statistically significant. 


\section{Results}

Of the 575 mothers studied, $46 \%$ were in the age category of 26-35 years. Furthermore, $29 \%$ of the mothers had secondary education and $36 \%$ had completed university or postgraduate education. Of the participants, $82 \%$ had two or more children aged 12 years old or younger. Participants' characteristics are outlined in Table 1.

A total of 334 of 575 (58\%) participants measured an accurate dose of paracetamol using an oral dosing syringe versus 286 (50\%) participants using the dropper and $292(51 \%)$ using the dosing cup. Participants most often measured an excessive dose with the dosing cup (249 participants [43\%]) compared with the syringe (73 participants [13\%]) and dropper (37 participants [6\%]). An underdose was measured most often with the dropper (252 participants [44\%]) and least often with the dosing cup (34 participants [6\%]). In general, participants measured more than the intended dose with the dosing cup and less than the intended dose with the dropper (Figure 1).

We found that age and pharmacist counseling did not affect dosing errors. In contrast, education status did have an effect; dosing accuracy for each type of instrument was significantly influenced by Saudi mothers' education statuses. Overdosing with dosing cup and syringe was much more prevalent in mothers who were in the illiterate and elementary education categories

Table I Characteristics of the study population $(n=575)$

\begin{tabular}{lll}
\hline Characteristic & $\begin{array}{l}\text { Number of } \\
\text { mothers }\end{array}$ & $\%$ \\
\hline Age (years) & 73 & 13 \\
I7-25 & 265 & 46 \\
$26-35$ & 190 & 33 \\
$36-45$ & 47 & 8 \\
46 and above & & \\
Education status & 29 & 5 \\
Illiterate & 84 & 15 \\
Elementary school & 86 & 15 \\
Middle school & 169 & 29 \\
High school & 207 & 36 \\
College and higher & & \\
Number of children & 102 & 18 \\
One & 473 & 82 \\
Two or more & & \\
Preferred measuring device & 240 & 30 \\
Dosing cup & 447 & 56 \\
Syringe & 63 & 8 \\
Dropper & 36 & 5 \\
Household spoon & 6 & 17 \\
Measuring spoon & & \\
Previous counseling & 133 & \\
Yes & 442 & \\
No & & \\
\hline
\end{tabular}

compared with high school and college graduates $(P<0.001)$, whereas underdosing using a dropper was more common in the latter population $(P<0.05)$. The effects of participants' demographic factors on dosing error using cup, syringe, and dropper are illustrated in Tables $2-4$, respectively.

\section{Discussion}

The results of the present study show that over $50 \%$ measured an accurate dose with the syringe more often than with the cup or dropper ( $\mathrm{n}=334$ [58\%]) and that most inaccuracies were made with the dropper $(\mathrm{n}=289[50 \%])$ and cup $(\mathrm{n}=282$ [49\%]). Our findings are consistent with those of previous studies in terms of the observed accuracy among different instruments. ${ }^{2,7}$ A study which compared the accuracy of a dosing cup and an oral dosing syringe showed that 23 of 96 (24\%) participants measured the accurate dose with the syringe and four of $96(4.2 \%)$ measured an accurate dose with the dosing cup $(P<0.001){ }^{2}$

Yin et al also found that the proportion of participants dosing accurately was only $50 \%$ using an etched marking cup and 30\% using a cup with printed marking. The study reported that dosing errors were much more prevalent with the use of cups compared with other instruments. ${ }^{7}$

Results from comparable studies indicated that parental education status is a strong predictor of dosing errors using measuring instruments. ${ }^{8}{ }^{9}$ Wallace et al reported that participants with a high school degree and beyond were 4.5 times more likely to measure the intended dose (95\% confidence interval [CI]: 1.56 , 13.25). ${ }^{8}$ Ravikiran and Shivarajashankara also found that lower education level was strongly linked with dosing error for three devices used to administer liquid medication: a dosing cup with etched markings, a $1 \mathrm{ml}$ medicine dropper and $5 \mathrm{ml}$ syringe. ${ }^{9}$

In the current study, 42 of the participants $(6 \%)$ selected the household or measuring spoon as their preferred liquid medication measuring device. Although this is a small percentage, this finding has serious consequences related to medication dosing errors. Yin et al reported that participants who used a household spoon had twice the odds of measuring an inaccurate dose (adjusted odds ratio $=2.3,95 \%$ CI: $1.2,4.4) .{ }^{10}$ Similar findings were reported by Ryu and Lee: dosing spoons and cups were associated with relatively high rates of dosing errors that exceeded $10 \%$ of the intended dose. ${ }^{11}$

One substantial finding in the present study was that 442 (77\%) mothers had not had previous counseling on the use of liquid medication measuring devices; nonetheless, a high percentage of mothers measured an accurate dose with the cup (228 [51.7\%]), syringe (254 [57.6\%]), and dropper 


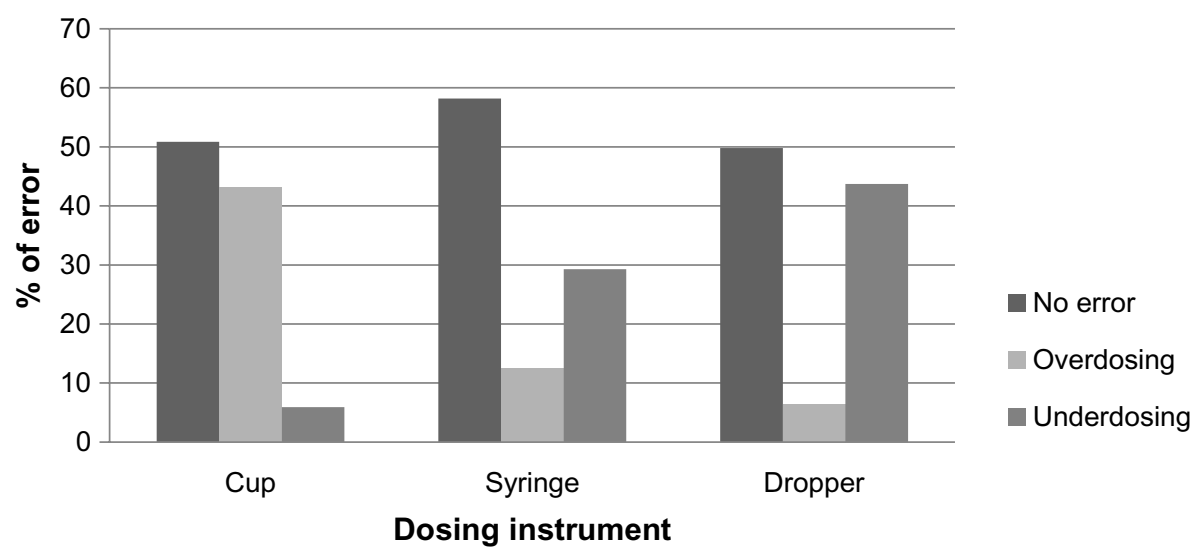

Figure I Observed dosing accuracy by dosing instrument type.

(217 [49.2\%]), which was contrary to our expectations. However, this result does not diminish the importance of pharmacist counseling on the proper use of liquid medication measuring devices. In a study that evaluated the accuracy of liquid medication administration before and after patient education, Peacock et al found that $88 \%$ and $85.6 \%$ of 125 patients measured nystatin with an error of greater than or equal to $20 \%$ before and after counseling, respectively. For digoxin, the totals were $24.8 \%$ before counseling and $4 \%$ after counseling. ${ }^{12}$

Table 2 Multinomial logistic regression to determine the effect of participants' demographic factors on dosing error using a cup

\begin{tabular}{|c|c|c|c|}
\hline Predictor factors & $\begin{array}{l}\text { Relative } \\
\text { risk ratio }\end{array}$ & $\begin{array}{l}95 \% \text { confidence } \\
\text { interval }\end{array}$ & $P$ \\
\hline \multicolumn{4}{|l|}{ Overdosing ${ }^{\mathrm{a}}$} \\
\hline \multicolumn{4}{|l|}{ Age $(\text { years })^{b}$} \\
\hline $26-35$ & 1.26 & $0.70-2.28$ & 0.42 \\
\hline $36-45$ & 0.68 & $0.35-1.31$ & 0.25 \\
\hline 46 and above & 0.81 & $0.34-1.91$ & 0.64 \\
\hline \multicolumn{4}{|l|}{ Education $^{c}$} \\
\hline Elementary school & 0.46 & $0.17-1.24$ & 0.12 \\
\hline Middle school & 0.34 & $0.12-0.93$ & 0.03 \\
\hline High school & 0.17 & $0.06-0.45$ & 0.00 \\
\hline College and higher & 0.15 & $0.06-0.41$ & 0.00 \\
\hline Number of children ${ }^{d}$ & 5.2 & $1.8-14.6$ & 0.001 \\
\hline Pharmacist counselinge & I.II & $0.73-1.69$ & 0.61 \\
\hline \multicolumn{4}{|l|}{ Underdosing ${ }^{a}$} \\
\hline \multicolumn{4}{|l|}{ Age $(\text { years })^{\mathrm{b}}$} \\
\hline $26-35$ & 0.40 & $0.13-1.19$ & 0.10 \\
\hline $36-45$ & 0.39 & $0.12-1.22$ & 0.01 \\
\hline 46 and above & 0.14 & $0.01-1.37$ & 0.09 \\
\hline \multicolumn{4}{|l|}{ Education $^{c}$} \\
\hline Elementary school & 0.19 & $0.0 I-3.6$ & 0.27 \\
\hline Middle school & 0.80 & $0.07-8.2$ & 0.85 \\
\hline High school & 0.90 & $0.09-8.3$ & 0.92 \\
\hline College and higher & 0.699 & $0.07-6.4$ & 0.75 \\
\hline Number of children ${ }^{d}$ & 4.00 & $0.33-47.2$ & 0.27 \\
\hline Pharmacist counselinge & 1.62 & $0.72-3.6$ & 0.23 \\
\hline
\end{tabular}

Notes: a No error was used as the base outcome; bthe age category 17-25 was used as reference; 'illiterate was used as reference; done child was used as reference; ${ }^{e n o}$ counseling was used as reference.
The most common practical issues encountered with syringe during the study were air bubbles and placement of the base of the rubber on the mark rather than the top of rubber. As a result, the actual amount of paracetamol in the syringe was less than intended. The same problem was found with the dropper. Most participants did not know how to use the dropper; therefore, $50 \%$ of participants made errors.

Consideration must be given to ensuring that all caregivers, including mothers, receive sufficient information

Table 3 Multinomial logistic regression to determine the effect of participants' demographic factors on dosing error using a syringe

\begin{tabular}{|c|c|c|c|}
\hline Predictor factors & $\begin{array}{l}\text { Relative } \\
\text { risk ratio }\end{array}$ & $\begin{array}{l}95 \% \text { confidence } \\
\text { interval }\end{array}$ & $P$ \\
\hline \multicolumn{4}{|l|}{ Overdosing ${ }^{a}$} \\
\hline \multicolumn{4}{|l|}{ Age (years) ${ }^{b}$} \\
\hline $26-35$ & 0.98 & $0.43-2.20$ & 0.96 \\
\hline $36-45$ & 0.63 & $0.24-1.62$ & 0.34 \\
\hline 46 and above & 1.08 & $0.3 \mathrm{I}-3.7$ & 0.90 \\
\hline \multicolumn{4}{|l|}{ Education $^{c}$} \\
\hline Elementary school & 0.29 & $0.09-0.88$ & 0.02 \\
\hline Middle school & 0.19 & $0.05-0.61$ & 0.005 \\
\hline High school & 0.08 & $0.02-0.26$ & 0.00 \\
\hline College and higher & 0.08 & $0.02-0.26$ & 0.00 \\
\hline Number of children ${ }^{d}$ & 3.77 & $1.14-12.4$ & 0.02 \\
\hline Pharmacist counselinge & 1.09 & $0.60-1.99$ & 0.76 \\
\hline \multicolumn{4}{|l|}{ Underdosing ${ }^{a}$} \\
\hline \multicolumn{4}{|l|}{ Age $\left(\right.$ years) ${ }^{\mathrm{b}}$} \\
\hline $26-35$ & 1.18 & $0.6 \mathrm{I}-2.28$ & 0.61 \\
\hline $36-45$ & 1.55 & $0.76-3.16$ & 0.227 \\
\hline 46 and above & 3.37 & $1.35-8.38$ & 0.009 \\
\hline \multicolumn{4}{|l|}{ Education ${ }^{c}$} \\
\hline Elementary school & 0.66 & $0.22-1.92$ & 0.44 \\
\hline Middle school & 0.58 & $0.19-1.73$ & 0.33 \\
\hline High school & 0.52 & $0.18-1.47$ & 0.22 \\
\hline College and higher & 0.52 & $0.18-1.44$ & 0.21 \\
\hline Number of children & 0.80 & $0.26-2.44$ & 0.70 \\
\hline Pharmacist counseling & 0.70 & $0.44-1.12$ & 0.14 \\
\hline
\end{tabular}

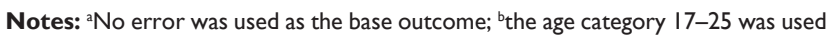
as reference; 'illiterate was used as reference; ${ }^{\circ}$ one child was used as reference; ${ }^{~}$ no counseling was used as reference. 
Table 4 Multinomial logistic regression to determine the effect of participants' demographic factors on dosing error using a dropper

\begin{tabular}{|c|c|c|c|}
\hline Predictor factors & $\begin{array}{l}\text { Relative } \\
\text { risk ratio }\end{array}$ & $\begin{array}{l}95 \% \text { confidence } \\
\text { interval }\end{array}$ & $P$ \\
\hline \multicolumn{4}{|l|}{ Overdosing ${ }^{\mathrm{a}}$} \\
\hline \multicolumn{4}{|l|}{ Age (years) ${ }^{\mathrm{b}}$} \\
\hline $26-35$ & 0.65 & $0.16-2.62$ & 0.55 \\
\hline $36-45$ & 0.85 & $0.20-3.48$ & 0.82 \\
\hline 46 and above & 0.56 & $0.07-4.06$ & 0.56 \\
\hline \multicolumn{4}{|l|}{ Education ${ }^{c}$} \\
\hline Elementary school & 2.23 & $0.23-21.7$ & 0.48 \\
\hline Middle school & 1.24 & $0.12-11.9$ & 0.85 \\
\hline High school & 0.54 & $0.05-5.39$ & 0.60 \\
\hline College and higher & 1.68 & $0.19-14.75$ & 0.63 \\
\hline Number of children ${ }^{d}$ & 3.58 & $0.26-48.9$ & 0.33 \\
\hline Pharmacist counseling ${ }^{e}$ & 1.24 & $0.56-2.74$ & 0.58 \\
\hline \multicolumn{4}{|l|}{ Underdosing ${ }^{\mathrm{a}}$} \\
\hline \multicolumn{4}{|l|}{ Age (years) ${ }^{b}$} \\
\hline $26-35$ & 0.51 & $0.29-0.92$ & 0.027 \\
\hline $36-45$ & 0.54 & $0.28-1.03$ & 0.063 \\
\hline 46 and above & 0.97 & $0.4 I-2.30$ & 0.95 \\
\hline \multicolumn{4}{|l|}{ Education $^{c}$} \\
\hline Elementary school & 0.96 & $0.36-2.56$ & 0.944 \\
\hline Middle school & 0.34 & $0.13-0.90$ & 0.03 \\
\hline High school & 0.28 & $0.11-0.72$ & 0.008 \\
\hline College and higher & 0.29 & $0.11-0.74$ & 0.009 \\
\hline Number of children ${ }^{d}$ & 3.18 & I.I8-8.54 & 0.022 \\
\hline Pharmacist counseling ${ }^{\mathrm{e}}$ & 0.82 & $0.54-1.25$ & 0.374 \\
\hline
\end{tabular}

Notes: ${ }^{\mathrm{N}} \mathrm{No}$ error was used as the base outcome; bthe age category 17-25 was used as reference; illiterate was used as reference; ${ }^{d}$;ne child was used as reference; ${ }^{e}$ no counseling was used as reference.

from the pharmacist on the proper use of liquid medication measuring devices and on how to read the calibration markings correctly to measure doses accurately. Several practical modalities have been proposed in practice and in the literature to reduce liquid medication dosing errors. Beyond Traditional Borders students at Rice University (Houston, TX, USA) designed a plastic syringe clip that fits into the barrel of a standard oral syringe to ensure that caregivers deliver the accurate dosage of liquid medication, regardless of literacy level, visual acuity, or manual dexterity. This clip locks into the syringe and stops the plunger when the desired amount of medication has been drawn. The clips are color-coded by dose and can be preset by a physician or pharmacist. ${ }^{13}$ This device could be provided to caregivers/mothers to ensure dosing accuracy. Moreover, a pictographic diagram could improve caregivers' dosing abilities and, thus, reduce dosing errors. In a study that assessed the use of a pictographic diagram to decrease parental dosing errors, Yin et al found that text-plus-pictogram recipients were less likely to make an error compared to text-only recipients $(43.9 \%$ versus $50.0 \% ; P=0.01) .{ }^{14}$ Furthermore, pharmacists could place a mark or sticker on the prescribed dose mark on the measuring device to facilitate dosing and ensure that no more/less than the required dose is measured. In addition, public campaigns which aim to address the proper use of liquid medication measuring devices could be useful.

Although data from the current study suggest that dose administration with the oral syringe was more accurate than with the dosing cup and dropper, these results should be interpreted with caution, as the study population predominantly consisted of highly educated Saudi mothers (36\%). Therefore, the present findings may not be generalizable to the average Saudi consumer. In some cases while doing the study we noted that lack of eye-level dose verification may be associated with dosing cup errors. Finally, the response rate was not measured and no sample size calculation was performed.

\section{Conclusion}

The current study found that mothers are at a high risk of making dosing errors when using a dropper and that education status plays an important role in dosing accuracy. Liquid dosing errors can be clinically significant; underdosing can result in lack of therapeutic response and overdosing can result in adverse drug events. ${ }^{11}$ In order to avoid dosing errors, pamphlets explaining how to use different kinds of measuring devices could be provided in the pharmacy. Furthermore, medication companies could add a diagram to their leaflets to demonstrate proper measuring with the provided device.

Further study using an accurate instrument, eg, a digital balance, to measure dosing errors is indicated. In addition, studies should be conducted to measure the percentage of dosing errors before and after patient counseling. Furthermore, studies that address how to improve the liquid medication dosing ability of Saudi mothers are needed.

\section{Acknowledgments}

The authors are especially grateful for the contributions of the participating hospitals (King Khlid University Hospital, Security Forces Hospital, Riyadh Care Hospital, and King Abdulaziz Medical City). We also thank the outpatient pharmacy service directors and staff for facilitating the data collection process. This research project was supported by a grant from the Research Center of the Center for Female Scientific and Medical Colleges, Deanship of Scientific Research, King Saud University.

\section{Disclosure}

The authors report no conflicts of interest in this work. 


\section{References}

1. Bates DW, Boyle DL, Vander Vliet MB, Schneider J, Leape L. Relationship between medication errors and adverse drug events. J Gen Intern Med. 1995;10(4):199-205.

2. Sobhani P, Christopherson J, Ambrose PJ, Corelli RL. Accuracy of oral liquid measuring devices: comparison of dosing cup and oral dosing syringe. Ann Pharmacother. 2008;42(1):46-52.

3. American Academy of Pediatrics. Committee on Drugs. Acetaminophen toxicity in children. Pediatrics. 2001;108(4):1020-1024.

4. Goldman RD, Scolnik D. Underdosing of acetaminophen by parents and emergency department utilization. Pediatr Emerg Care. 2004; 20(2):89-93.

5. FDA's Safe Use Initiative: Collaborating to Reduce Preventable Harm from Medications. US Department of Health and Human Services Food and Drug Administration; 2009 [cited October 20, 2014]. Available from: http://www.fda.gov/downloads/Drugs/DrugSafety/UCM188961. pdf. Accessed November 4, 2014.

6. FEVADOL ${ }^{\circledR}$ (paracetamol) [package insert]. SPIMACO; 2011 [cited October 20, 2014]. Available from: http://www.spimaco.com.sa/ getattachment/c024dd5d-1094-4ff4-8de0-c8ed5cc50379/Fevadol.aspx. Accessed November 4, 2014.

7. Yin HS, Mendelsohn AL, Wolf MS, et al. Parents' medication administration errors: role of dosing instruments and health literacy. Arch Pediatr Adolesc Med. 2010;164(2):181-186.
8. Wallace LS, Keenum AJ, DeVoe JE, Bolon SK, Hansen JS. Women's understanding of different dosing instructions for a liquid pediatric medication. J Pediatr Health Care. 2012;26(6):443-450.

9. Ravikiran SR, Shivarajashankara YM. Dosing ability of Indian parents for liquid medication. Indian Pediatr. 2011;48(2):153-154.

10. Yin HS, Dreyer BP, Ugboaja DC, et al. Unit of measurement used and parent medication dosing errors. Pediatrics. 2014;134(2):e354-e361.

11. Ryu GS, Lee YJ. Analysis of liquid medication dose errors made by patients and caregivers using alternative measuring devices. J Manag Care Pharm. 2012;18(6):439-445.

12. Peacock G, Parnapy S, Raynor S, Wetmore S. Accuracy and precision of manufacturer-supplied liquid medication administration devices before and after patient education. J Am Pharm Assoc (2003). 2010;50(1):84-86.

13. DoseRight Syringe Clip. Houston, TX: Rice University; 2012 [cited October 20, 2014]. Available from: http://rice360.rice.edu/Resources/ Documents/DoseRight\%20Syringe\%20Clip.final.pdf. Accessed November 4, 2014.

14. Yin HS, Mendelsohn AL, Fierman A, van Schaick L, Bazan IS, Dreyer BP. Use of a pictographic diagram to decrease parent dosing errors with infant acetaminophen: a health literacy perspective. Acad Pediatr. 2011;11(1):50-57.
Drug, Healthcare and Patient Safety

\section{Publish your work in this journal}

Drug, Healthcare and Patient Safety is an international, peer-reviewed open-access journal exploring patient safety issues in the healthcare continuum from diagnostic and screening interventions through to treatment, drug therapy and surgery. The journal is characterized by the rapid reporting of reviews, original research, clinical, epidemiological and

\section{Dovepress}

post-marketing surveillance studies, risk management, health literacy and educational programs across all areas of healthcare delivery. The manuscript management system is completely online and includes a very quick and fair peer-review system. Visit http://www.dovepress.com/ testimonials.php to read real quotes from published authors. 